\title{
Relative hyperlactatemia and hospital mortality in critically ill patients: a retrospective multi-centre study
}

\author{
Alistair D Nichol*1,3, Moritoki Egi22, Ville Pettila1, Rinaldo Bellomo 1,4, Craig French55, Graeme Hart4, Andrew Davies³, \\ Edward Stachowski6, Michael C Reade ${ }^{4}$, Michael Bailey 1,3 and David James Cooper1,3
}

\begin{abstract}
Introduction: Higher lactate concentrations within the normal reference range (relative hyperlactatemia) are not considered clinically significant. We tested the hypothesis that relative hyperlactatemia is independently associated with an increased risk of hospital death.

Methods: This observational study examined a prospectively obtained intensive care database of 7,155 consecutive critically ill patients admitted to the Intensive Care Units (ICUs) of four Australian university hospitals. We assessed the relationship between ICU admission lactate, maximal lactate and time-weighted lactate levels and hospital outcome in all patients and also in those patients whose lactate concentrations (admission $n=3,964$, maximal $n=2,511$, and timeweighted $\mathrm{n}=4,584$ ) were under 2 mmol..-1 (i.e. relative hyperlactatemia).

Results: We obtained 172,723 lactate measurements. Higher admission and time-weightedlactate concentration within the reference range was independently associated with increased hospital mortality (admission odds ratio (OR) 2.1, 95\% confidence interval (CI) 1.3 to 3.5, $P=0.01$; time-weighted OR 3.7, $95 \% \mathrm{Cl} 1.9$ to $7.00, P<0.0001$ ). This significant association was first detectable at lactate concentrations $>0.75 \mathrm{mmol} . \mathrm{L}^{-1}$. Furthermore, in patients whose lactate ever exceeded 2 mmol.L-1, higher time-weighted lactate remained strongly associated with higher hospital mortality (OR $4.8,95 \% \mathrm{Cl} 1.8$ to $12.4, P<0.001)$.
\end{abstract}

Conclusions: In critically ill patients, relative hyperlactataemia is independently associated with increased hospital mortality. Blood lactate concentrations $>0.75 \mathrm{mmol}^{-1} \mathrm{~L}^{-1} \mathrm{can}$ be used by clinicians to identify patients at higher risk of death. The current reference range for lactate in the critically ill may need to be re-assessed.

\section{Introduction}

In healthy individuals there is a continuous cycle of lactate production and metabolism, which ensures that blood lactate concentrations are normally low [1,2]. Higher blood lactate concentrations occur when lactate production exceeds clearance, when clearance capacity is decreased or more frequently when both occur simultaneously $[3,4]$. Elevated blood lactate concentrations above the accepted normal reference range (absolute hyperlactataemia) are common and associated with increased hospital mortality in the critically ill [5-12]. Their usefulness in identifying criti-

* Correspondence: Alistair.Nichol@med.monash.edu.au

1 Australian and New Zealand Intensive Care-Research Centre, School of Public Health and Preventive Medicine, Monash University, Alfred Hospital Campus,

75 Commercial Road, Prahran, VIC 31821, Australia cally ill patients at higher risk of death has led to the adoption of lactate measurement in most blood gas analyzers and the frequent measurement of lactate in the critically ill.

While the normal lactate concentration in unstressed individuals is $1.0 \pm 0.5 \mathrm{mmol} . \mathrm{L}^{-1}[1,2]$, patients with critical illness are considered to have normal lactate levels at concentrations of less than 2 mmol.L-1 $[13]$. Furthermore, this 2 mmol.L-1 cut off may be considered to be a conservative threshold as some have suggested that a level of up to 4 mmol. $\mathrm{L}^{-1}$ is within the normal limits [14].

However, it is unknown whether a higher blood lactate concentration within the current reference range (relative hyperlactataemia) might also be associated with increased hospital mortality. This knowledge would be clinically important because the currently used upper reference limit 
for lactatemia may fail to identify many patients who are at higher risk of death.

We hypothesized that higher blood lactate concentrations within the reference range would be associated with an increased risk of hospital death and investigated the relationship between ICU admission, maximal and timeweighted blood lactate concentrations and hospital mortality in a large cohort of critically ill patients.

\section{Materials and methods}

The data collection and the data analysis for this study are part of ongoing de-identified data auditing processes across the participating hospitals, which have all waived the need for informed consent. The Austin Hospital Ethics Committee approved the study.

\section{Study population and data sources}

We conducted this study as a four-centre retrospective investigation of a prospectively gathered intensive care database. Four Australian university teaching hospital intensive care units enrolled patients in this study. We included all patients admitted to these ICUs from January 2000 to October 2004

The blood lactate concentration data used for this study were stored and retrieved electronically. We obtained age, sex, use of mechanical ventilation, reason for ICU admission, surgical and non-surgical divided into (trauma, cardiac/vascular, gastrointestinal tract, neurological and thoracic/respiratory diseases), and Acute Physiology and Chronic Health Evaluation (APACHE) II score [15] from the electronic data repositories of each ICU, using prospectively collected data as part of a continuing data collection by the Australian and New Zealand Intensive Care Society Centre for Outcome and Resources Evaluation (ANZICSCORE). We coded admission diagnosis by APACHE III system used by the ANZICS-CORE - Adult Patient Database [16].

All patients had initial arterial lactate and blood gas measured by blood gas analyser (Rapilab, Bayer Australia, Sydney, NSW, Australia, upper normal limit $2.00 \mathrm{mmol}^{-L^{-1}}$ ) at the time of admission to the ICU. The timing of repeat measurements was at the discretion of the managing critical care team. All subsequent blood lactate measurements were performed using the same blood-gas analyzer in each hospital. A normal (within reference) lactate was defined as a concentration between 0.00 and $2.00 \mathrm{mmol}^{-1} \mathrm{~L}^{-1}$ [13]. Laboratories in the participating hospitals comply with standards of the National Association of Testing Authorities [17] and the Royal College of Pathologists of Australasia [18].

\section{Statistical Analysis}

We used the ICU admission ( $\mathrm{Lac}_{\mathrm{ADM}}$ ) and maximal (LacMAX) blood lactate concentrations to indicate the admission and highest value recorded while in the ICU. We first assessed blood lactate concentration in all patients and second, in those patients whose ICU admission ( $\mathrm{Lac}_{\mathrm{ADM}}$ ), and maximal $\left(\mathrm{Lac}_{\mathrm{MAX}}\right)$ blood lactate concentrations never exceeded the normal reference range (that is, $<2 \mathrm{mmol}$. L $\left.{ }^{1}\right)$. In addition, to avoid the potential effect of surveillance bias due to the increased blood lactate monitoring in more severely ill patients, we calculated the time-weighted lactate concentration $\left(\mathrm{Lac}_{\mathrm{TW}}\right)$. This time-weighted method is more representative of the true lactate level during the ICU stay than the arithmetic mean, as it assumes a linear trend between each individual lactate measurement for each patient during their ICU stay. This method was modified from, and used in accordance with, an approach previously used by Finney et al to describe hyperglycaemia [19].

As the relationship between $\mathrm{Lac}_{\mathrm{ADM}}, \mathrm{Lac}_{\mathrm{MAX}}, \mathrm{Lac}_{\mathrm{TW}}$ and mortality was expected not to be linear in nature, categorical variables were created. We divided lactate into four bands: normal ( 0.00 to 2.00 mmol.L-1); mild hyperlactemia (2.01 to $4.00 \mathrm{mmol} . \mathrm{L}^{-1}$ ); moderate hyperlactatemia (4.01 to $6.00 \mathrm{mmol}^{\left.-\mathrm{L}^{-1}\right)}$ and severe hyperlactatemia $(>6.01$ mmol. $L^{-1}$ ) for comparison.

The normal range of lactate $\left(0.00\right.$ to $\left.2.00 \mathrm{mmol}^{-\mathrm{L}^{-1}}\right)$ was subsequently divided into eight bands. However, due to the small number of patients with values under $<0.75 \mathrm{mmol}$. L ${ }^{1}$ we combined the three lower octiles to achieve adequate size for statistical comparison. We therefore compared: the lower limit of normal (LLN, 0.00-0.75 mmol.L-1); upper limit of normal (ULN, 1.76 to $2.00 \mathrm{mmol}^{-\mathrm{L}^{-1}}$ ) and four intermediate categories $\left(0.75\right.$ to $\left.1.00 \mathrm{mmol}^{-1}\right)$; $(1.01$ to $\left.1.25 \mathrm{mmol} . \mathrm{L}^{-1}\right) ;(1.26$ to $1.50 \mathrm{mmol.L}-1) ;(1.51$ to 1.75 mmol. $\left.\mathrm{L}^{-1}\right)$.

To confirm that any association between $\mathrm{Lac}_{\mathrm{TW}}$ levels within the normal range and mortality was not being biased by patients who had individual lactate concentrations above 2 mmol.L-1 while in the ICU, we then examined the association between $\mathrm{Lac}_{\mathrm{TW}}$ and mortality in the cohort of patients whose lactate never exceeded 2 mmol.L-1 ${ }^{-1}$.

The primary outcome for analysis was hospital mortality and the secondary outcome was ICU mortality. We performed crude univariate analysis with lactate as a catagorial variable for comparison between groups according to hospital survival status using chi-square test for proportions, Student t-test for normally distributed outcomes and Wilcoxon rank sum tests otherwise. In addition, we performed multivariate analysis where we adjusted for all available predictors of hospital mortality included in the models (gender, age, APACHE II, mechanical ventilation, surgical admission and diagnosis type) determined by backward elimination of non-significant variables. Furthermore, to determine if the lactate associations were consistent across patient admission diagnosis subgroups and study hospitals, we examined the interactions between measures of lactate 
and other variables in the model. We report results from the multivariate models using odds ratios, OR $(95 \%$ confidence intervals, 95\% CI).

All analyses were performed using SAS version 9.2 (SAS Institute Inc, Cary, NC, USA). A two-sided $P$-value of 0.05 was considered to be statistically significant.

\section{Results}

We studied a heterogeneous cohort of 7,155 critically ill patients with 172,723 blood lactate measurements (Table 1). The absolute blood lactate concentrations (admission lactate $\mathrm{Lac}_{\mathrm{ADM}}$, maximal lactate $\mathrm{Lac}_{\mathrm{MAX}}$ and time-weighted lactate $\mathrm{Lac}_{\mathrm{TW}}$ ), were significantly higher in non-survivors compared to survivors (Table 1).

\section{Overall assessment of hyperlactatemia (absolute hyperlactatemia)}

A higher crude $\mathrm{Lac}_{\mathrm{ADM}}, \mathrm{Lac}_{\mathrm{MAX}}$ and $\mathrm{Lac}_{\mathrm{TW}}$ concentration above the reference range $\left(0.00\right.$ to $\left.2.00 \mathrm{mmol} . \mathrm{L}^{-1}\right)$ was associated with a higher hospital and ICU mortality rate (Figure 1, Panel a, b, c, respectively). Multivariate analysis showed that compared to the current reference lactate concentration $\left(0.00\right.$ to $\left.2.00 \mathrm{mmol} . \mathrm{L}^{-1}\right)$ a higher $\operatorname{Lac}_{\mathrm{ADM}}(>8$ mmol.L-1), $\operatorname{Lac}_{\mathrm{MAX}}(>10 \mathrm{mmol.L}-1)$ and $\operatorname{Lac}_{\mathrm{TW}}(>6$ mmol. $\mathrm{L}^{-1}$ ) blood lactate concentration was strongly associated with an increased adjusted hospital mortality ( $\mathrm{Lac}_{\mathrm{ADM}}$ OR213.49 (95\% CI 28.69 to 1588.71), $P<0.0001)$; Lac $_{\text {MAX }}$ OR8.44 (95\% CI 5.99 to 11.91$), P<0.0001) \mathrm{Lac}_{\mathrm{TW}} \mathrm{OR}$ 37.78 (95\% CI 18.72 to 76.25$), P<0.0001)$. This association between lactate $\left(\mathrm{Lac}_{\mathrm{ADM}}, \mathrm{Lac}_{\mathrm{MAX}}\right.$ and $\left.\mathrm{Lac}_{\mathrm{TW}}\right)$ and adjusted mortality was independent of admission diagnosis, admission hospital and APACHE II score.

\section{Assessment of relative hyperlactatemia}

We further identified the cohorts of patients with a $\mathrm{Lac}_{\mathrm{ADM}}$ $(\mathrm{n}=3,964), \mathrm{Lac}_{\mathrm{MAX}},(\mathrm{n}=2,511)$ and with $\mathrm{Lac}_{\mathrm{TW}}(\mathrm{n}=$ $4,584)$ within the current reference range $(0.00$ to 2.00 mmol. $\left.\mathrm{L}^{-1}\right)$. Table 2 shows the clinical characteristics of the $\mathrm{Lac}_{\mathrm{ADM}}$ subgroup of patients divided into hospital survivors and non-survivors. Patients with an admission or time weighted lactate level just below 2 mmol.L-1 had a crude hospital mortality rate of approximately $20 \%$ (Figures $2 \mathrm{a}$ and $3 b$ ). $\mathrm{Lac}_{\mathrm{ADM}}, \mathrm{Lac}_{\mathrm{MAX}}$ and $\mathrm{Lac}_{\mathrm{TW}}$ were significantly higher in hospital non-survivors compared to survivors (Table 2).

A higher admission lactate $\left(\mathrm{Lac}_{\mathrm{ADM}}\right)$ concentration within the reference range was associated with higher crude hospital mortality (Figure 2a), with a mortality rate of $18.5 \%$ in the higher risk cohort. There also was a significant independent relationship between $\mathrm{Lac}_{\mathrm{ADM}}$ within the reference range and adjusted hospital mortality (Figure 2b). Higher $\mathrm{Lac}_{\mathrm{TW}}$ within the reference range was independently associated with higher adjusted hospital mortality (Figure $3 b)$ with a crude mortality rate of $21.1 \%$ in the higher risk cohort (Figure 3a). In addition, higher $\mathrm{Lac}_{\mathrm{TW}}$ (1.5 to 2.00 mmol. $\mathrm{L}^{-1}$ vs 0.00 to $0.75 \mathrm{mmol} . \mathrm{L}^{-1}$ ) was also independently associated with hospital mortality in the cohort of patients whose lactate never exceeded $2 \mathrm{mmol}^{-1} \mathrm{~L}^{-1}\left(\mathrm{Lac}_{\mathrm{TW}} \mathrm{OR} 4.8\right.$, $95 \%$ CI 1.8 to $12.4, P<0.001, \mathrm{n}=2,254)$.

The association between adjusted hospital mortality and $\mathrm{Lac}_{\mathrm{ADM}}$ and $\mathrm{Lac}_{\mathrm{TW}}$ lactate concentrations within the normal range was first detected at lactate concentrations over 0.75 mmol.L-1 and the strength of this association increased with higher lactate concentrations within the reference range (Figures $2 \mathrm{~b}$ and $3 \mathrm{~b}$ ). The detected association between lactate within the reference range and adjusted hospital mortality was independent of admission diagnosis, admission hospital and APACHE II score. Interestingly, a higher crude and adjusted maximal lactate ( $\left.\mathrm{Lac}_{\mathrm{MAX}}\right)$ concentration within the normal reference range was not independently associated with increased hospital mortality (data not shown).

\section{Discussion}

\section{Statement of key findings}

We tested whether higher levels of lactatemia within the current reference range (relative hyperlactemia) are independently associated with an increased risk of hospital mortality. We found that most patients admitted to ICU had an admission or time weighted lactate level within the current normal reference range and yet a crude hospital mortality rate of approximately $20 \%$. We also found that higher ICU admission ( $\left.\mathrm{Lac}_{\mathrm{ADM}}\right)$ and time weighted $\left(\mathrm{Lac}_{\mathrm{TW}}\right)$ blood lactate concentrations within the normal reference range were strongly and independently associated with hospital mortality. In addition, this increased mortality risk was first detected at lactate concentrations above $0.75 \mathrm{mmol}^{-\mathrm{L}^{-1}}$.

\section{Comparison with previous studies}

Many studies have found that either $\mathrm{Lac}_{\mathrm{ADM}}$ or $\mathrm{Lac}_{\mathrm{MAX}}$ above the reference range are associated with higher mortality following cardiothoracic surgery [12], trauma [7], major abdominal surgery [5], high risk surgery, major vascular trauma, sepsis [20], liver disease [21], in ventilated neonates [22] and critically ill children [11]. Our observations that the extent of absolute hyperlactatemia is strongly linked with mortality independent of admission diagnostic group in a large mixed cohort of critically ill patients confirm that lactate is a useful marker in the intensive care setting to identify patients at high risk of death. In addition, these findings suggest that other observations related to lactate obtained from our cohort might also be generalizable. In addition, we found that time weighted lactate $\left(\mathrm{Lac}_{\mathrm{TW}}\right)$, a representation of the lactate concentration throughout the ICU stay, was strongly associated with increasing hospital 
Table 1: Clinical characteristics of hospital survivors and non-survivors

\begin{tabular}{|c|c|c|c|c|c|}
\hline & $\mathbf{n}$ & $\begin{array}{c}\text { Hospital } \\
\text { Non-survivors }\end{array}$ & $\mathbf{n}$ & $\begin{array}{l}\text { Hospital } \\
\text { Survivors }\end{array}$ & P-value \\
\hline Male Sex & 1,561 & $57.3 \%(894)$ & 5,590 & $60.2 \%(3,365)$ & 0.035 \\
\hline APACHE II score & 1,250 & $24.6(8.1)$ & 4,845 & $15.1(6.6)$ & $<0.0001$ \\
\hline Age (yr) & 1,428 & $65.8(16.6)$ & 5,181 & $59.7(18.9)$ & $<0.0001$ \\
\hline $\begin{array}{l}\text { Number on mechanical } \\
\text { ventilation }\end{array}$ & 1,434 & $81.2 \%(1164)$ & 5,515 & $55.6 \%(3,066)$ & $<0.0001$ \\
\hline Surgical patients & 1,565 & $28.4 \%(444)$ & 5,590 & $48.7 \%(2,722)$ & $<0.0001$ \\
\hline \multicolumn{6}{|l|}{ Diagnosis at admission } \\
\hline Cardiac and vascular & 1,565 & $26 \%(407)$ & 5,590 & $21.6 \%(1,207)$ & 0.0003 \\
\hline Thoracic and respiratory & 1,565 & $18.5 \%(290)$ & 5,590 & $18.9 \%(1,057)$ & 0.69 \\
\hline Trauma & 1,565 & $2.2 \%(34)$ & 5,590 & $7.9 \%(442)$ & $<0.0001$ \\
\hline Neurological & 1,565 & $14.1 \%(221)$ & 5,590 & $10.9 \%(609)$ & 0.0004 \\
\hline $\begin{array}{l}\text { Gastrointestinal tract } \\
\text { diseases }\end{array}$ & 1,565 & $14.1 \%(221)$ & 5,590 & $22.9 \%(1,280)$ & $<0.0001$ \\
\hline Other & 1,565 & $25 \%(391)$ & 5,590 & $17.7 \%(989)$ & $<0.0001$ \\
\hline ICU stay (days) & 1,559 & $3.0(1.5$ to 6.6$)$ & 5,589 & 2.5 (1.6 to 4.9$)$ & $<0.0001$ \\
\hline Hospital stay (days) & 1,312 & 9 (3 to 24$)$ & 5,131 & 14 (8 to 29 ) & $<0.0001$ \\
\hline $\begin{array}{l}\text { Admission blood lactate } \\
\text { (mmom.L-1) }\end{array}$ & 1,395 & $2.3(1.4$ to 4.4$)$ & 5,037 & $1.5(1.0$ to 2.4$)$ & $<0.0001$ \\
\hline $\begin{array}{l}\text { Time-weighted blood lactate } \\
\text { (mmom.L-1) }\end{array}$ & 1,411 & $2.0(1.4$ to 3.3$)$ & 4,977 & $1.3(1.0$ to 1.8 & $<0.0001$ \\
\hline Max blood lactate (mmom.L-1) & 1,565 & $4.0(2.2$ to 7.5$)$ & 5,590 & 2.1 (1.4 to 3.3$)$ & $<0.0001$ \\
\hline
\end{tabular}

Data are expressed as, percentage (number), (standard deviation) or median (interquartile range).

APACHE II, Acute Physiology and Chronic Health Evaluation II.

mortality. The finding that the duration of this derangement while in the ICU is associated with increased mortality expands previous work demonstrating that periods of sustained hyperlactataemia (that is, ongoing excess production or decreased clearance of lactate) is associated with an increased risk of death [3,5,23-28].

To our knowledge, this is the first study to assess the relationship of higher lactate concentrations within the current reference range and mortality. We found a strong association between an increased $\mathrm{Lac}_{\mathrm{ADM}}$ and $\mathrm{Lac}_{\mathrm{TW}}$ within the current reference range and increased hospital mortality. Furthermore, we demonstrated that higher $\mathrm{Lac}_{\mathrm{TW}}$ in the cohort of patients whose lactate ever exceeded 2 mmol.L-1 was also strongly associated with higher hospital mortality. These results suggest that relative hyperlactaemia may be useful in identifying critically ill patients at high risk of death. Furthermore, we have demonstrated that the higher mortality associated with higher lactate levels $\left(\mathrm{Lac}_{\mathrm{ADM}}\right.$ and $\mathrm{Lac}_{\mathrm{TW}}$ ) within the normal reference range is detectable at all concentrations $>0.75 \mathrm{mmol} . \mathrm{L}^{-1}$ compared to 0.00 to
$0.75 \mathrm{mmol} . \mathrm{L}^{-1}$. In their aggregate, these results suggest that the transition from physiological to pathological lactatemia occurs at a concentration well below $2.00 \mathrm{mmol} . \mathrm{L}^{-1}$ and that an elevated $\mathrm{Lac}_{\mathrm{ADM}}$ and/or $\mathrm{Lac}_{\mathrm{TW}}>0.75 \mathrm{mmol} . \mathrm{L}^{-1}$ identifies critically ill patients at higher risk of death.

\section{Implications for clinicians}

These findings expand our understanding of lactate as a clinical biomarker in the ICU. Relatively small changes in lactate homeostasis as detected by higher blood concentrations within the reference range may reflect important otherwise undetected physiological changes, which may reflect widespread metabolic stress [29] and increased use of lactate as a fuel source [30].

A higher time weighted lactate ( $\mathrm{Lac}_{\mathrm{TW}}$ ) below 2 mmol.L1 , the cohort of patients whose lactate ever exceeded 2 mmol.L-1, was also strongly associated with increased hospital mortality. This finding extends our understanding of the reference range by emphasizing the role of the duration of lactate derangement in predicting increased risk of death 


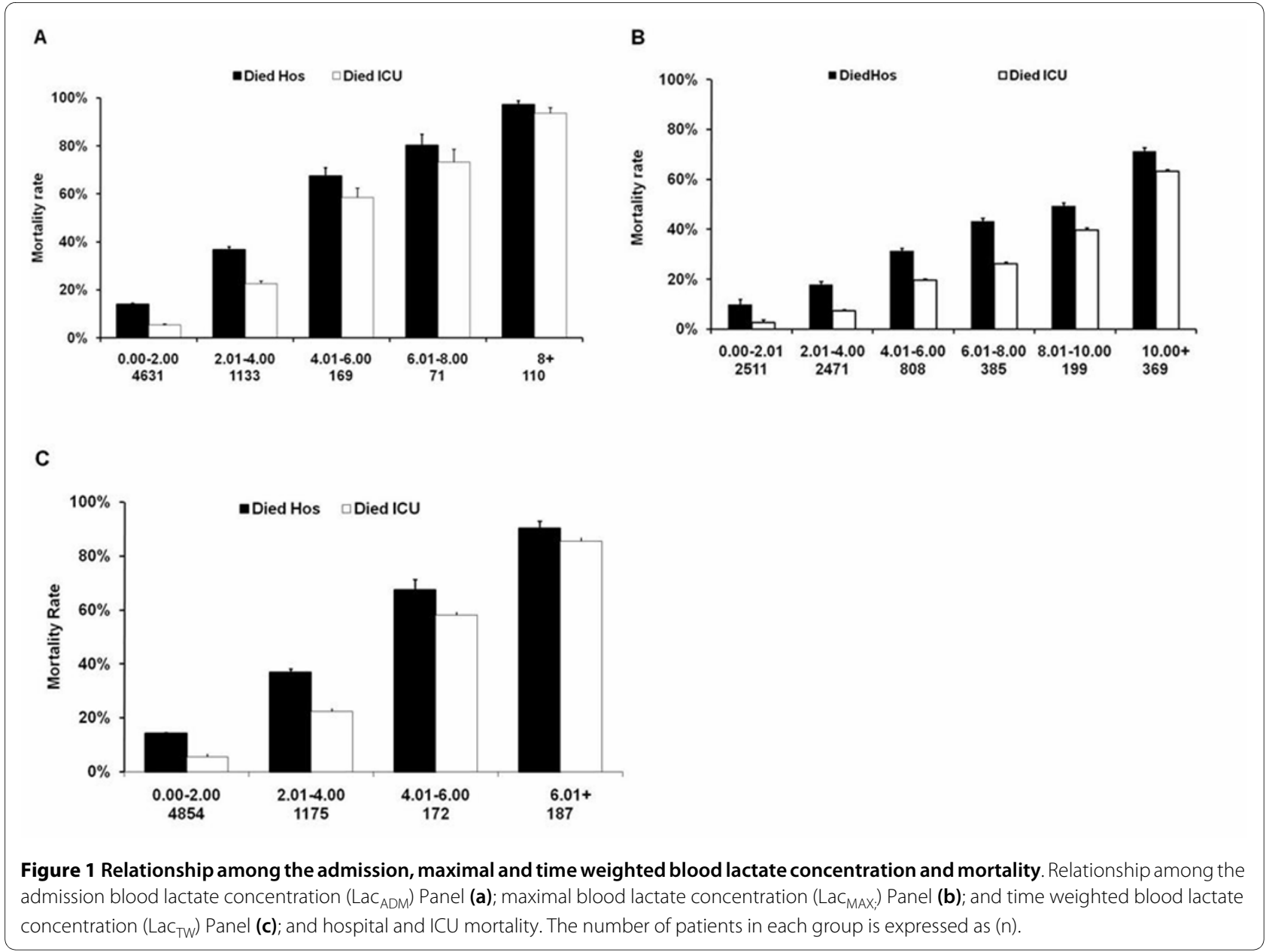

$[3,5,23-25,28,31,32]$. Furthermore, it highlights the clinical importance of persistently higher lactate concentrations. This notion may explain why $\mathrm{Lac}_{\mathrm{TW}}$ (which reflects the extent and duration of the derangement) but not $\mathrm{Lac}_{\mathrm{MAX}}$ (which only reflects its momentary extent) predicted mortality within the reference range.

Our results suggest that ICU clinicians confronted with a patient with a $\mathrm{Lac}_{\mathrm{ADM}}$ or $\mathrm{Lac}_{\mathrm{TW}}$ (persistently higher lactate) over $0.75 \mathrm{mmol}^{\mathrm{L}} \mathrm{L}^{-1}$ should look for any remediable causes of physiological stress and appreciate that these patients are at increased risk of an adverse outcome.

\section{Strengths and limitations of the study}

The strengths of our study include the fact that it is the largest investigation of lactatemia in a general multicenter cohort of patients, thus carrying a higher degree of external validity. It used data from $>170,000$ measurements obtained with state-of the-art technology, thus increasing their accuracy and reproducibility. It used robust and clinically relevant outcomes. It is the first to study the independent relationship between relative hyperlactatemia and outcome and identified clinically relevant findings. Limita- tions of the study include the fact that it is retrospective in design and thus potentially subject to systematic error and bias. However, all the clinical and electronic data utilised were collected prospectively in a large number of consecutive critically ill patients in four ICUs. The data are numerical in nature and were measured independently; thus they were not amenable to selection bias or unintended manipulation. A number of common ICU therapeutic interventions such as epinephrine [33], metformin [34], nucleoside analogues in HIV [35], high-volume hemofiltration (HVHF) with lactate-buffered replacement fluids [36] can all affect lactate levels and we did not have information on their use. We were therefore unable to include these in our multivariate analyses. However, the size of our study and the strength of the association between $\mathrm{Lac}_{\mathrm{ADM}}$ and $\mathrm{Lac}_{\mathrm{TW}}$ and mortality within the reference range independent of admission diagnosis and hospital suggest that these factors are not likely to have confounded the signal in this study. Despite this, clinicians should be aware of the potential of these iatrogenic causes of relative or absolute hyperlactataemia. Due to the smaller numbers of patients in the cohort with $\mathrm{Lac}_{\mathrm{ADM}}$ and $\mathrm{Lac}_{\mathrm{TW}}$ in the lowest three octiles, we com- 



Figure 2 Relationship between the admission blood lactate concentration within the normal range and mortality rate. Relationship between the admission blood lactate $\left(\mathrm{LaC}_{\mathrm{ADM}}\right)$ concentration within the normal range and ICU and hospital mortality rate (Panel (a)). The number of patients in each group is expressed as (n). Panel (b) displays the result (adjusted odds ratios (OR) with 95\% Confidence Interval (Cl)) of a multivariate analysis assessing the association between admission blood lactate ( LaC $_{\mathrm{ADM}}$ ) within the normal range and hospital mortality. (All ORs in the multivariate analysis are compared to the 0.00 to $0.75 \mathrm{mmol}^{-L^{-1}}$ group with the horizontal line representing an OR of 1.0.).

pressed these octiles into a single group ( 0.00 to 0.75 mmol. $\mathrm{L}^{-1}$ ) to provide sufficient numbers for statistical analyses. This compression limited our ability to determine if higher blood lactate concentrations below $0.75 \mathrm{mmol}^{-\mathrm{L}^{-1}}$ may also be associated with increasing mortality.

\section{Future research}

Our findings are novel and need to be confirmed by similar studies in other countries or patient populations before they can be considered to reflect a general biological principle. Such studies should ideally be performed prospectively with a simultaneous collection of information on interven- tions, which may affect lactate by dilution (intravenous fluids) or by changing its metabolism (drugs) and these studies should ideally also include non-ICU cohorts of patients (that is, Emergency Department patients). If these studies confirm the value of relative hyperlactatemia, the reference value for lactate in critically ill patients may require adjustment.

\section{Conclusions}

In conclusion, higher $\mathrm{Lac}_{\mathrm{ADM}}$ and $\mathrm{Lac}_{\mathrm{TW}}$ blood lactate concentrations within the current reference range are associated with greater hospital mortality. These results suggest that 
A
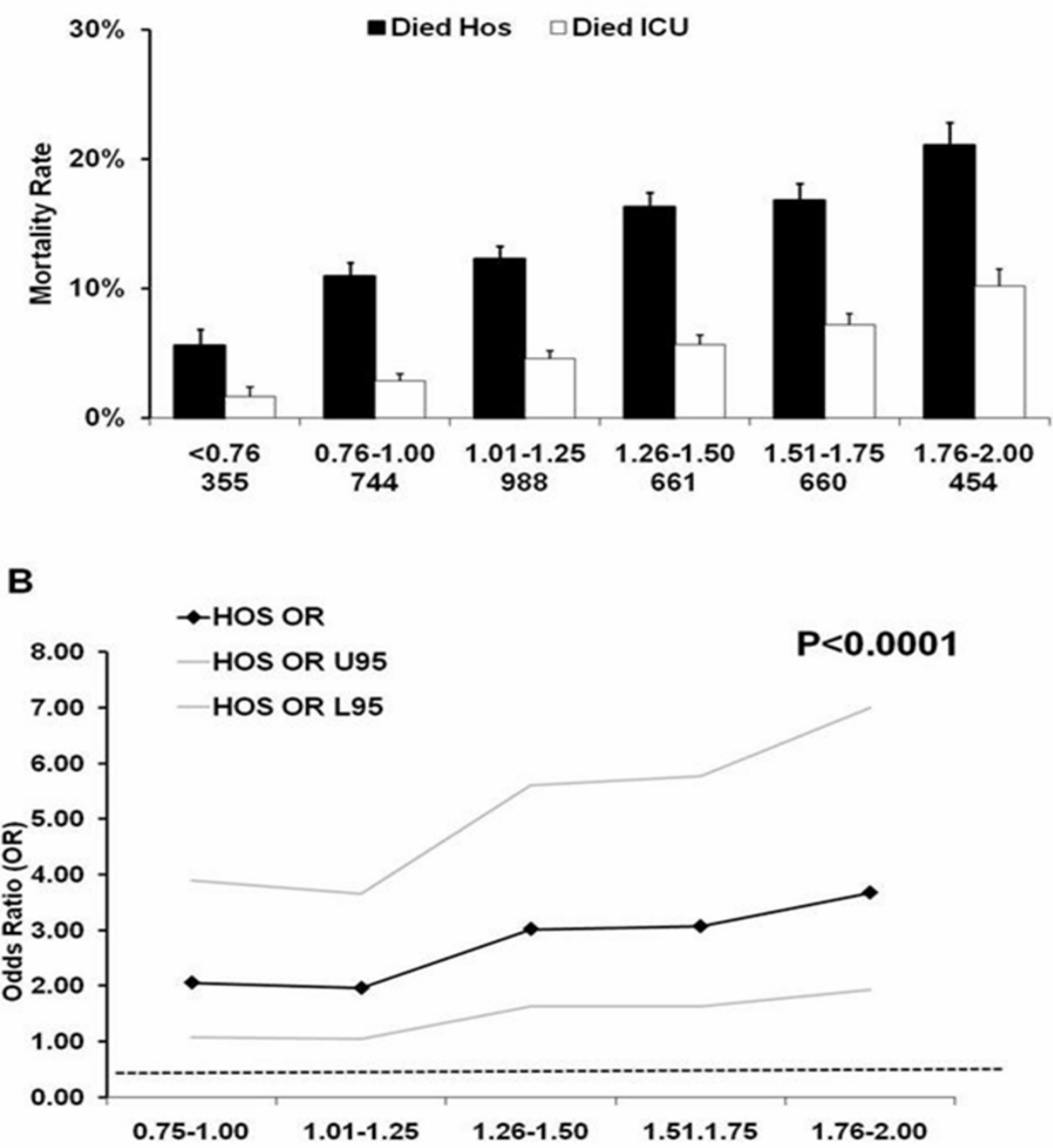

Figure 3 Relationship between time-weighted blood lactate concentration within the normal range and mortality rate. Relationship between time-weighted blood lactate $\left(\mathrm{LaC}_{\mathrm{TW}}\right)$ concentration within the reference range and ICU and hospital mortality rate (Panel (a)). The number of patients in each group is expressed as (n). Panel (b) displays the result (adjusted odds ratios (OR) with 95\% Confidence Interval (CI)) of a multivariate analysis assessing the association between time-weighted blood lactate concentration ( $\left.\mathrm{LaC}_{\mathrm{TW}}\right)$ within the normal range and hospital mortality. Abbreviations: OR U95; odds ratio upper $95 \% \mathrm{Cl}$; OR L95, odds ratios lower $95 \% \mathrm{Cl}$. (All ORs in the multivariate analysis are compared to 0.00 to $0.75 \mathrm{mmol} . \mathrm{L}-$ 1 group with the horizontal line representing an OR of 1.0.).

even relative hyperlactaemia is a useful biomarker in critical illness. They also suggest that the upper level of the reference value for lactate in critically ill patients may require readjustment. Finally, they imply that clinicians should be especially alert in all patients with admission and/or persistent blood lactate concentrations within the current upper limit of the reference range.

\section{Key messages}

- Blood lactate concentration is increasingly being measured in the critically ill.

- Higher intensive care unit blood lactate concentrations above the current normal range (absolute hyperlactatemia) are associated with increased hospital mortality.

- Higher intensive care unit admission blood lactate concentrations within the current normal range (relative 
Table 2: Clinical characteristics for hospital survivors and non-survivors in patients with admission blood lactate concentration within the reference range

\begin{tabular}{|c|c|c|c|c|c|}
\hline & $\mathbf{n}$ & $\begin{array}{l}\text { Hospital } \\
\text { Non-survivors }\end{array}$ & $\mathbf{n}$ & $\begin{array}{l}\text { Hospital } \\
\text { Survivors }\end{array}$ & P-value \\
\hline Male Sex & 607 & $58.2 \%(353)$ & 3,357 & $59 \%(1,981)$ & 0.71 \\
\hline APACHE II score & 485 & $22.1(7.3)$ & 2,891 & $14.2(6.2)$ & $<0.0001$ \\
\hline Age (yr) & 556 & $66.0(16.5)$ & 3,090 & $60.7(18.7)$ & $<0.0001$ \\
\hline Number on mechanical ventilation & 551 & $77.3 \%(426)$ & 3,313 & $48.7 \%(1,613)$ & $<0.0001$ \\
\hline Surgical patients & 607 & $31 \%(188)$ & 3,357 & $50.9 \%(1,709)$ & $<0.0001$ \\
\hline \multicolumn{6}{|l|}{ Diagnosis at admission } \\
\hline Cardiac and vascular & 607 & $15.2 \%(92)$ & 3,357 & $20.4 \%(685)$ & 0.003 \\
\hline Thoracic and respiratory & 607 & $24.2 \%(147)$ & 3,357 & $20 \%(671)$ & 0.017 \\
\hline Trauma & 607 & $3.6 \%(22)$ & 3,357 & $8.8 \%(295)$ & $<0.0001$ \\
\hline Neurological & 607 & $18.1 \%(110)$ & 3,357 & $10.9 \%(366)$ & $<0.0001$ \\
\hline Gastrointestinal tract diseases & 607 & $15.3 \%(93)$ & 3,357 & $23.7 \%(796)$ & $<0.0001$ \\
\hline Other & 607 & $23.6 \%(143)$ & 3,357 & $16.2 \%(544)$ & $<0.0001$ \\
\hline ICU stay (days) & 606 & $3.0(2.0$ to 8.0$)$ & 3,357 & $2.0(1.3$ to 4.0$)$ & $<0.0001$ \\
\hline Hospital stay (days) & 501 & $12.9(5.2$ to 30.2$)$ & 3,064 & 13.0 (7.9 to 26.7$)$ & 0.041 \\
\hline Admission blood lactate (mmom.L-1) & 607 & 1.3 (1 to 1.6$)$ & 3,357 & $1.2(0.9$ to 1.5$)$ & $<0.0001$ \\
\hline $\begin{array}{l}\text { Time-weighted blood lactate } \\
\text { (mmom.L-1) }\end{array}$ & 599 & 1.4 (1.1 to 1.9$)$ & 3,212 & $1.20(1.0$ to 1.5$)$ & $<0.0001$ \\
\hline Max blood lactate (mmom.L-1) & 607 & $2.4(1.6$ to 4.1$)$ & 3,357 & $1.7(1.3$ to 2.4$)$ & $<0.0001$ \\
\hline
\end{tabular}

Data are expressed as, percentage (number), (standard deviation) or median (interquartile range) APACHE II, Acute Physiology and Chronic Health Evaluation II.

hyperlactatemia) are associated with increased hospital mortality.

- Higher time weighted intensive care unit blood lactate concentrations within the current normal range (relative hyperlactatemia) are associated with increased hospital mortality.

- Higher blood lactate concentrations within the current normal range can be used to identify patients at high risk of death; possibly suggesting that we need to revise the current definition of normal blood lactate concentration in the critically ill.

\section{Abbreviations}

ANZICS-APD: Australian and New Zealand Intensive Care Society - Adult Patient Database; ANZICS-CORE: Australian and New Zealand Intensive Care Society - Centre for Outcome and Resources Evaluation; APACHE: Acute Physiological and Chronic Health Evaluation; LLN: lower limit of normal; LaC $C_{A D M}$

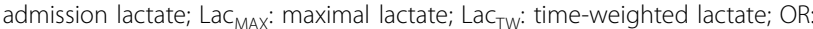
odds ratio; ULN: upper limit of normal.

\section{Competing interests}

The authors declare that they have no competing interests.

\section{Authors' contributions}

$A N, R B, V P, G H, D J C, M B$ and ES carried out the database searches, participated in the data collation and drafted the manuscript with $A D, C F, E S, M R$. AN, RB, VP,
DJC, MB conceived of the study, and participated in its design and coordination and helped to draft the manuscript. All authors read and approved the final manuscript.

\section{Acknowledgements}

No financial support was received for the collation of this article.

\section{Author Details}

${ }^{1}$ Australian and New Zealand Intensive Care-Research Centre, School of Public Health and Preventive Medicine, Monash University, Alfred Hospital Campus, 75 Commercial Road, Prahran, VIC 31821, Australia, 2Department of Anaesthesiology and Resuscitology, 2-5-1 Shikata-cho, Okayama, 700-8558, Japan, ${ }^{3}$ Department of Intensive Care, The Alfred Hospital, 75 Commercial Road, Prahran, VIC 31821, Australia, ${ }^{4}$ Department of Intensive Care, The Austin Hospital, 145 Studley Road, Heidelberg, VIC 3084, Australia, 5Department of Intensive Care, The Western Hospital, 148 Gordon Street, Footscray, VIC 3011 , Australia and ${ }^{6}$ Department of Intensive Care, Westmead Hospital, Darcy Road \& Hawksebury Road, Westmead, Sydney, NSW 2145, Australia

Received: 25 January 2010 Accepted: 24 February 2010 Published: 24 February 2010

\section{References}

1. De Backer D: Lactic acidosis. Intensive Care Med 2003, 29:699-702.

2. De Backer D: Lactic acidosis. Minerva Anestesio/ 2003, 69:281-284.

3. Manikis P, Jankowski S, Zhang H, Kahn RJ, Vincent JL: Correlation of serial blood lactate levels to organ failure and mortality after trauma. Am J Emerg Med 1995, 13:619-622. 
4. Vincent JL, Dufaye P, Berre J, Leeman M, Degaute JP, Kahn RJ: Serial lactate determinations during circulatory shock. Crit Care Med 1983 11:449-451.

5. Husain FA, Martin MJ, Mullenix PS, Steele SR, Elliott DC: Serum lactate and base deficit as predictors of mortality and morbidity. Am J Surg 2003, 185:485-491.

6. Basaran M, Sever K, Kafali E, Ugurlucan M, Sayin OA, Tansel T, Alpagut U, Dayioglu E, Onursal E: Serum lactate level has prognostic significance after pediatric cardiac surgery. J Cardiothorac Vasc Anesth 2006. 20:43-47.

7. Cerovic O, Golubovic V, Spec-Marn A, Kremzar B, Vidmar G: Relationship between injury severity and lactate levels in severely injured patients. Intensive Care Med 2003, 29:1300-1305.

8. Jansen TC, van Bommel J, Woodward R, Mulder PG, Bakker J: Association between blood lactate levels, Sequential Organ Failure Assessment subscores, and 28-day mortality during early and late intensive care unit stay: a retrospective observational study. Crit Care Med 2009, 37:2369-2374

9. Khosravani H, Shahpori R, Stelfox HT, Kirkpatrick AW, Laupland KB: Occurrence and adverse effect on outcome of hyperlactatemia in the critically ill. Crit Care 2009, 13:R90

10. Jansen TC, van Bommel J, Mulder PG, Rommes JH, Schieveld SJ, Bakker J: The prognostic value of blood lactate levels relative to that of vital signs in the pre-hospital setting: a pilot study. Crit Care 2008, 12:R160.

11. Koliski A, Cat I, Giraldi DJ, Cat ML: [Blood lactate concentration as prognostic marker in critically ill children]. J Pediatr (Rio J) 2005, 81:287-292.

12. Toraman F, Evrenkaya S, Yuce M, Aksoy N, Karabulut H, Bozkulak Y, Alhan C: Lactic acidosis after cardiac surgery is associated with adverse outcome. Heart Surg Forum 2004, 7:E155-159.

13. Mizock BA: Lactic acidosis. Dis Mon 1989, 35:233-300

14. Rivers E, Nguyen B, Havstad S, Ressler J, Muzzin A, Knoblich B, Peterson E, Tomlanovich M: Early goal-directed therapy in the treatment of severe sepsis and septic shock. N Engl J Med 2001, 345:1368-1377.

15. Knaus WA, Draper EA, Wagner DP, Zimmerman JE: APACHE II: a severity of disease classification system. Crit Care Med 1985, 13:818-829.

16. ANZICS AaNZICS: Modified APACHE III admission diagnosis. [http:// www.anzics.com.au].

17. National Association of Testing Authorities [http://www.nata.asn.au]

18. RCPA Manual. In The Royal College of Pathologists of Australasia Fifth edition. The Royal College of Pathologists of Australasia Sydney; 2009.

19. Finney SJ, Zekveld C, Elia A, Evans TW: Glucose control and mortality in critically ill patients. Jama 2003, 290:2041-2047.

20. Park M, Azevedo LC, Maciel AT, Pizzo VR, Noritomi DT, da Cruz Neto LM: Evolutive standard base excess and serum lactate level in severe sepsis and septic shock patients resuscitated with early goal-directed therapy: still outcome markers? Clinics 2006, 61:47-52

21. Kruse JA, Zaidi SA, Carlson RW: Significance of blood lactate levels in critically ill patients with liver disease. Am J Med 1987, 83:77-82.

22. Deshpande SA, Platt MP: Association between blood lactate and acidbase status and mortality in ventilated babies. Arch Dis Child Fetal Neonatal Ed 1997, 76:F15-20.

23. Abramson D, Scalea TM, Hitchcock R, Trooskin SZ, Henry SM, Greenspan J: Lactate clearance and survival following injury. J Trauma 1993, 35:584-588. discussion 588-589.

24. McNelis J, Marini CP, Jurkiewicz A, Szomstein S, Simms HH, Ritter G, Nathan IM: Prolonged lactate clearance is associated with increased mortality in the surgical intensive care unit. Am J Surg 2001, 182:481-485.

25. Kalyanaraman M, DeCampli WM, Campbell Al, Bhalala U, Harmon TG, Sandiford P, McMahon CK, Shore S, Yeh TS: Serial blood lactate levels as a predictor of mortality in children after cardiopulmonary bypass surgery. Pediatr Crit Care Med 2008, 9:285-288.

26. Jansen TC, van Bommel J, Mulder PG, Lima AP, Hoven B van der, Rommes $\mathrm{JH}$, Snellen FT, Bakker J: Prognostic value of blood lactate levels: does the clinical diagnosis at admission matter? J Trauma 2009, 66:377-385.

27. Levraut J, Ichai C, Petit I, Ciebiera JP, Perus O, Grimaud D: Low exogenous lactate clearance as an early predictor of mortality in normolactatemic critically ill septic patients. Crit Care Med 2003, 31:705-710.

28. Yang CS, Qiu HB, Huang YZ, Xie JF, Mo M, Liu SQ, Yang Y: [Prospective research on the prognosis of septic shock based on the change of lactate concentration in arterial blood]. Zhonghua Wai Ke Za Zhi 2009, 47:685-688.

29. Gladden LB: Lactate metabolism: a new paradigm for the third millennium. J Physio/ 2004, 558:5-30

30. Leverve XM: Lactate in the intensive care unit: pyromaniac, sentinel or fireman? Crit Care 2005, 9:622-623.

31. Bakker J, Gris P, Coffernils M, Kahn R, Vincent J: Serial blood lactate levels can predict the devlopment of multiple organ failure fllowing septic shock. Am J Surg 1996, 171:221-226.

32. Cardinal Fernandez PA, Olano E, Acosta C, Bertullo H, Albornoz H, Bagnulo $\mathrm{H}$ : Prognostic value of lactate clearance in the first 6 hours of intensive medicine course. Med Intensiva 2009, 33:166-170.

33. Myburgh JA, Higgins A, Jovanovska A, Lipman J, Ramakrishnan $N$ Santamaria J: A comparison of epinephrine and norepinephrine in critically ill patients. Intensive Care Med 2008.

34. Chang CT, Chen YC, Fang JT, Huang CC: Metformin-associated lactic acidosis: case reports and literature review. J Nephrol 2002, 15:398-402.

35. Falco V, Crespo M, Ribera E: Lactic acidosis related to nucleoside therapy in HIV-infected patients. Expert Opin Pharmacother 2003, 4:1321-1329.

36. Cole L, Bellomo R, Baldwin I, Hayhoe M, Ronco C: The impact of lactatebuffered high-volume hemofiltration on acid-base balance. Intensive Care Med 2003, 29:1113-1120.

doi: $10.1186 / \mathrm{cc} 8888$

Cite this article as: Nichol et al., Relative hyperlactatemia and hospital mortality in critically ill patients: a retrospective multi-centre study Critical Care 2010, 14:R25 